\title{
Perbedaan Tinggi, Jumlah Daun, dan Diameter Batang Tanaman Jagung (Zea mays L.) pada Sistem Agroforestri Penanaman Lorong (Alley Cropping) dan Tumpang Sari di DAS Mikro Desa Tukad Sumaga, Kecamatan Gerokgak, Kabupaten Buleleng
}

\section{WAYAN GEDE WIRYANATA*), MADE MIKA MEGA ASTUTHI, DAN KADEK AYU CHARISMA JULIA DEWI}

Program Studi Agroteknologi, Fakultas Pertanian dan Bisnis, Universitas Dwijendra, Jl. Kamboja No.17, Dangin Puri Kangin, Kec. Denpasar Utara, Bali 80232, Indonesia

${ }^{*}$ E-mail: yandewiryanata@gmail.com

\begin{abstract}
Differences in Height, Number of Leaves, and Stem Diameter of Corn (Zea mays L.) in Alley Cropping and Intercropping of Agroforestry Systems at the Micro Watershed of Tukad Sumaga Village, Gerokgak District, Buleleng Regency. Degraded land as a result of land conversion has a very bad impact on the agro-ecosystem. Land conversion caused by the increasing needs of the population. The majority of the livelihoods of the people in Tukad Sumaga village are farmers. The availability of forage is very important to be maintained. Corn plants, in addition to their production in the form of corn, forage fodder on corn plants are very important for the availability of cattle feed. This research was conducted on 28 DAP maize (Zea mays L.) in alley cropping system and intercropping in the micro watershed of Tukad Sumaga Village. The results showed that the highest average plant height, leaf number, and corn stalk diameter were found in the alley cropping system namely $1.03 \mathrm{~m}, 7.31$, and $1.59 \mathrm{~cm}$. There was no significant difference between the height of corn plants in alley cropping and intercropping systems. There is a significant difference between the number of leaves and the diameter of the stems of maize in alley cropping and intercropping systems.
\end{abstract}

Keywords: plant heights, number of leaves, stem diameter of corn plants, agroforestry system

PENDAHULUAN

Lahan yang terdegradasi sebagai akibat dari alih fungsi lahan sangat berdampak buruk bagi agroekosistem. Alih fungsi lahan umumnya disebabkan oleh kebutuhan penduduk yang semakin meningkat. Pengelolaan lahan kering tidak akan optimal tanpa penerapan teknik konservasi yang memadai (Haerani, 2017). Agroforestri merupakan salah satu cara 
I WAYAN GEDE WIRYANATA et al. Perbedaan Tinggi, Jumlah Daun, dan Diameter...

menanggulangi dampak negatif dari alih fungsi lahan. Penanaman berbagai macam pohon dengan atau tanpa tanaman setahun (semusim) pada lahan yang sama sudah sejak lama dilakukan petani di Indonesia (Mokoginta, 2016). Agroforestri merupakan salah satu bentuk multiple cropping yang telah banyak dikembangkan terutama di daerah-daerah up-land dan disekitar kawasan hutan (Mokoginta, 2016). Sistem agroforestri umumnya lebih produktif daripada sistem penggunaan lahan tanpa pohon (Triwanto, 2019). Pepohonan mampu menjaga kestabilan lereng perbukitan dan menahan hilangnya tanah akibat erosi dan aliran air (Rahayu dkk., 2009). Simbiosis mutualisme antara pohon dengan tanaman semusim dapat menjaga kestabilan iklim mikro, seperti terjaganya kecepatan angin, kelembaban tanah dan udara, serta memberikan naungan (Widianto dkk., 2003). Penutupan vegetasi di suatu wilayah DAS berkaitan erat dengan masalah konservasi tanah dan air dimana hutan sebagai salah satu penyangga utama dalam sistem DAS (Indriyanto, 2008). Penggunaan lahan pada DAS Mikro desa Tukad Sumaga seluas 212,700 ha $(28,68 \%)$ berada di luar kawasan hutan dan 542,500 ha $(71,84 \%)$ merupakan hutan negara (BPDAS Unda Anyar, 2003). Mayoritas mata pencaharian penduduk di desa Tukad Sumaga adalah petani. Selain bertani, masyarakat juga memelihara ternak sapi dan babi. Ketersediaan akan hijauan pakan ternak untuk ternak sapi sangatlah penting untuk dijaga. Tanaman jagung, selain hasil produksinya berupa jagung, hijauan pakan ternak pada tanaman jagung sangat penting bagi ketersediaan pakan ternak sapi.

Penelitian ini sangat penting sebagai dasar untuk memberikan pemahaman dan pengetahuan baru bagi dunia penelitian dan masyarakat di sekitar kawasan hutan tentang perbedaan tinggi, jumlah daun, dan diameter batang pada pertumbuhan tanaman jagung sistem agroforestri penanaman lorong (alley cropping) dan tumpang sari. Sistem agroforestri yang dikembangkan secara tepat dengan mengedepankan prinsip-prinsip hutan lestari dan menjaga ekosistem akan mampu meningkatkan pendapatan masyarakat dan meningkatkan kualitas lingkungan. Tujuan penelitian ini adalah untuk mengetahui perbedaan pertumbuhan tanaman jagung (tinggi, jumlah daun, dan diameter batang) pada sistem agroforestri penanaman lorong (alley cropping) dan tumpang sari di DAS Mikro Desa Tukad Sumaga. 


\section{BAHAN DAN METODE}

Penelitian dilakukan pada dua lokasi di DAS Mikro Tukad Sumaga yang secara administratif terletak di Desa Tukad Sumaga, Kecamatan Gerokgak, Kabupaten Buleleng. Dua lokasi tersebut adalah lokasi sistem agroforestri penanaman lorong (alley cropping) dan tumpang sari. Survey awal penelitian dilaksanakan pada bulan November sampai Desember 2020. Pengambilan sampel penelitian dilaksanakan pada bulan Februari sampai Maret 2021.

Alat yang digunakan untuk menganalisis vegetasi dalam penelitian antara lain: patok bambu dan tali plastik untuk membuat petak ukur, pita ukur untuk mengukur tinggi vegetasi tanaman, penggaris, kamera digital untuk dokumentasi, alat tulis untuk mencatat datadata di lapangan dan seperangkat laptop untuk analisis data dan menyusun laporan. Bahan yang digunakan dalam penelitian ini adalah vegetasi tanaman jagung yang terdapat pada petak-petak ukur sistem agroforestri penanaman lorong (alley cropping) dan tumpang sari di DAS Mikro Desa Tukad Sumaga, Kecamatan Gerokgak, Kabupaten Buleleng. Pengambilan data primer meliputi tinggi, jumlah daun, dan diameter batang tanaman jagung.
Pengambilan data primer menggunakan metode penelitian plot ganda. Plot ganda adalah plot coba yang dibuat dalam suatu areal lahan yang dianalisa lebih dari satu. Peletakan plot ganda secara random atau acak. Total luas plot coba ganda harus berdasarkan dengan Intensitas Sampling (IS) yang digunakan. Intensitas sampling yang digunakan adalah $1 \%$. Wilayah agroforestri pertama-tama dibuat petak ukur. Pengambilan sampel tanaman jagung dilakukan dengan menggunakan metode Purposive Sampling. Purposive Sampling merupakan metode pengambilan sampel tanaman dengan meletakkan plotplot penelitian yang dianggap paling mewakili dan cocok untuk dijadikan sebagai plot penelitian, vegetasinya tidak terlalu rapat maupun tidak terlalu jarang (Hairiah dan Rahayu, 2007).

Hasil pengukuran tinggi, jumlah daun, dan diameter batang tanamanJagung di lapangan direkap menggunakan Microsoft Excel kemudian di uji menggunakan Uji-t. Uji-t digunakan untuk membandingkan rata-rata dua kelompok yang bersifat independen (Sarwono dan Herlina, 2012). Hasil analisis dijabarkan dalam tabel untuk memperoleh signifikasi hasil. 
I WAYAN GEDE WIRYANATA et al. Perbedaan Tinggi, Jumlah Daun, dan Diameter...

\section{HASIL DAN PEMBAHASAN}

Hasil Pengamatan tinggi, jumlah daun, dan diameter batang tanaman jagung pada sistem agroforestri penanaman lorong (alley cropping) dan tumpang sari di DAS mikro Desa Tukad Sumaga, Kecamatan Gerokgak, Kabupaten Buleleng dapat dilihat pada Tabel 1.

Tabel 1. Hasil rata-rata tinggi, jumlah daun, diameter batang tanaman jagung 28 HST

\begin{tabular}{lccc}
\hline Sistem agroforestri & $\begin{array}{c}\text { Rata-rata tinggi } \\
\text { tanaman jagung } \\
(\mathrm{m})\end{array}$ & $\begin{array}{c}\text { Rata-rata jumlah } \\
\text { daun tanaman } \\
\text { jagung }\end{array}$ & $\begin{array}{c}\text { Rata-rata diameter } \\
\text { batang tanaman } \\
\text { jagung }(\mathrm{cm})\end{array}$ \\
\hline $\begin{array}{l}\text { Penanaman } \\
\text { (alley cropping })\end{array}$ & 1,03 & 7,31 & 1,59 \\
\hline Tumpang sari. & 0,85 & 6,19 & 1,41 \\
\hline
\end{tabular}

Dari Tabel 1 diperoleh hasil bahwa rata-rata tertinggi tinggi tanaman, jumlah daun dan diameter batang tanaman jagung terdapat pada sistem agroforestri penanaman lorong (alley cropping). Hal ini membuktikan bahwa sistem agroforestri penanaman lorong (alley cropping) memberikan pengaruh yang lebih tinggi terhadap tinggi, jumlah daun, dan diameter batang tanaman jagung di bandingkan sistem agroforestri tumpang sari. Sistem alley cropping dapat mengendalikan kehilangan hara baik melalui erosi maupun runoff (Wang., dkk, 2010).

Tabel 2. Hasil uji-t statistik tinggi tanaman jagung

\begin{tabular}{|c|c|c|c|c|c|c|c|c|c|}
\hline \multicolumn{10}{|c|}{ Independent Samples Test } \\
\hline & & $\begin{array}{l}\text { Levene's } \\
\text { Test for } \\
\text { Equality of } \\
\text { Variances } \\
\end{array}$ & \multicolumn{7}{|c|}{ t-test for Equality of Means } \\
\hline & & F Sig. & \multirow[t]{2}{*}{$\mathrm{t}$} & \multirow[t]{2}{*}{ df } & \multirow[t]{2}{*}{$\begin{array}{l}\text { Sig. (2- } \\
\text { tailed) }\end{array}$} & \multirow[t]{2}{*}{$\begin{array}{c}\text { Mean } \\
\text { Difference }\end{array}$} & \multirow[t]{2}{*}{$\begin{array}{l}\text { Std. Error } \\
\text { Difference }\end{array}$} & \multicolumn{2}{|c|}{$\begin{array}{l}95 \% \text { Confidence } \\
\text { Interval of the } \\
\text { Difference }\end{array}$} \\
\hline & & & & & & & & Lower & Upper \\
\hline \multirow[t]{2}{*}{$\overline{\text { Tinggi }}$} & $\begin{array}{l}\text { Equal } \\
\text { variances } \\
\text { assumed } \\
\end{array}$ & $\begin{array}{ll}.079 & .782\end{array}$ & 1.455 & 18 & .163 & .17700 & .12165 & -.07858 & .43258 \\
\hline & $\begin{array}{l}\text { Equal } \\
\text { variances } \\
\text { not } \\
\text { assumed }\end{array}$ & & 1.455 & 16.499 & .164 & .17700 & .12165 & -.08026 & .43426 \\
\hline
\end{tabular}


Agrotrop : Journal on Agriculture Science, 11 (2): 107 - 114 (2021)

Berdasarkan output di atas diketahui nilai Sig. Levene's Test for Eguality of Variances sebesar 0,782 >0,05, maka dapat diartikan bahwa varians data pada kedua sistem agroforestri adalah homogen. Berdasarkan tabel output "Independent Samples Test" pada bagian "Equal variances assumed" diketahui nilai Sig. (2- tailed) sebesar 0,163>0,05 maka $\mathrm{H} 0$ diterima dan Ha ditolak. Dengan demikian dapat disimpulkan bahwa tidak ada perbedaan yang nyata (signifikan) antara tinggi tanaman jagung pada sistem agroforestri penanaman lorong (alley cropping) dan tumpang sari.

Tabel 3. Hasil analisis T tabel statistik jumlah daun tanaman jagung

\begin{tabular}{|c|c|c|c|c|c|c|c|c|c|c|}
\hline \multicolumn{11}{|c|}{ Independent Samples Test } \\
\hline & & \multicolumn{2}{|c|}{$\begin{array}{l}\text { Levene's Test } \\
\text { for Equality } \\
\text { of Variances }\end{array}$} & \multicolumn{7}{|c|}{ t-test for Equality of Means } \\
\hline & & \multirow[t]{2}{*}{$\mathrm{F}$} & \multirow[t]{2}{*}{ Sig. } & \multirow[t]{2}{*}{$\mathrm{t}$} & \multirow[t]{2}{*}{$\mathrm{df}$} & \multirow[t]{2}{*}{$\begin{array}{l}\text { Sig. (2- } \\
\text { tailed) }\end{array}$} & \multirow[t]{2}{*}{$\begin{array}{c}\text { Mean } \\
\text { Differenc } \\
\mathrm{e}\end{array}$} & \multirow[t]{2}{*}{$\begin{array}{l}\text { Std. Error } \\
\text { Differenc } \\
\text { e }\end{array}$} & \multicolumn{2}{|c|}{$\begin{array}{l}\text { 95\% Confidence } \\
\text { Interval of the } \\
\text { Difference }\end{array}$} \\
\hline & & & & & & & & & Lower & Upper \\
\hline \multirow[t]{2}{*}{$\begin{array}{l}\text { Jumlah } \\
\text { daun }\end{array}$} & $\begin{array}{l}\text { Equal } \\
\text { variances } \\
\text { assumed }\end{array}$ & 2.535 & .129 & 4.474 & 18 & .000 & 1.12300 & .25098 & .59570 & 1.65030 \\
\hline & $\begin{array}{l}\text { Equal } \\
\text { variances } \\
\text { not } \\
\text { assumed }\end{array}$ & & & 4.474 & $\begin{array}{r}13.94 \\
9\end{array}$ & .001 & 1.12300 & .25098 & .58451 & 1.66149 \\
\hline
\end{tabular}

Berdasarkan output di atas diketahui nilai Sig. Levene's Test for Eguality of Variances sebesar 0,129>0,05, maka dapat diartikan bahwa varians data pada kedua sistem agroforestri adalah homogen. Berdasarkan tabel output "Independent Samples Test" pada bagian "Equal variances assumed" diketahui nilai Sig. (2- tailed) sebesar $0,000<0,05$ maka $\mathrm{H} 0$ ditolak dan Ha diterima. Dengan demikian dapat disimpulkan bahwa terdapat perbedaan yang nyata (signifikan) antara jumlah daun tanaman jagung pada sistem agroforestri penanaman lorong (alley cropping) dan tumpang sari. 
I WAYAN GEDE WIRYANATA et al. Perbedaan Tinggi, Jumlah Daun, dan Diameter...

Tabel 4. Hasil analisis T table statistik diameter batang tanaman jagung

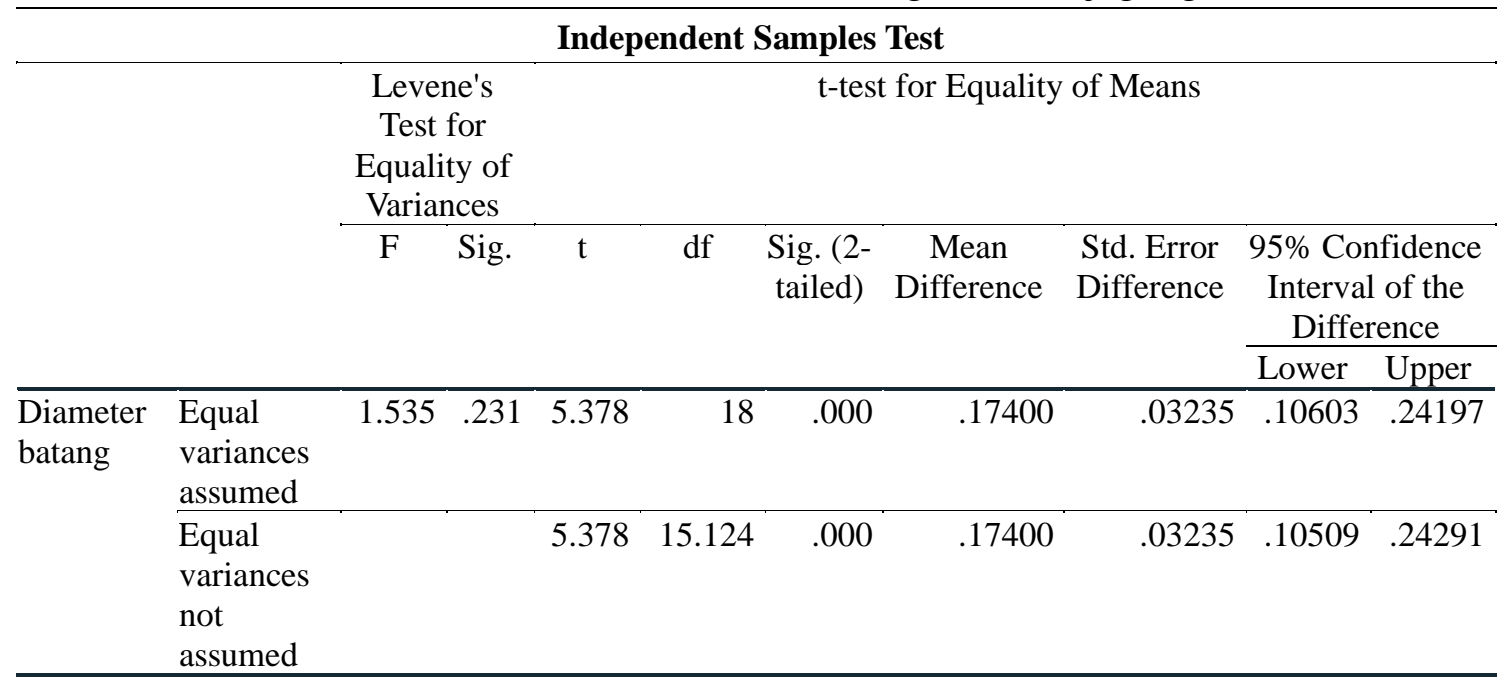

Berdasarkan output di atas diketahui nilai Sig. Levene's Test for Eguality of Variances sebesar 0,231>0,05, maka dapat diartikan bahwa varians data pada kedua sistem agroforestri adalah homogen. Berdasarkan tabel output "Independent Samples Test" pada bagian "Equal variances assumed" diketahui nilai Sig. (2- tailed) sebesar $0,000<0,05$ maka $\mathrm{H} 0$ ditolak dan Ha diterima. Dengan demikian dapat disimpulkan bahwa ada perbedaan yang nyata (signifikan) antara diameter batang tanaman jagung pada sistem agroforestri penanaman lorong (alley cropping) dan tumpang sari.

Tabel 5. Hasil analisis $\mathrm{T}$ tabel statistik tinggi, jumlah daun, dan diameter batang tanaman jagung

\begin{tabular}{lcc}
\hline \multicolumn{1}{c}{ Parameter } & $\mathrm{t}$ & Sig. (2-tailed) \\
\hline Tinggi tanaman jagung $(\mathrm{m})$ & 1.455 & .163 \\
Jumlah daun tanaman jagung & 4.474 & .000 \\
Diameter batang tanaman jagung & 5.378 & .000 \\
\hline
\end{tabular}

Berdasarkan tabel 5, nilai Sig. (2- tinggi tanaman jagung pada sistem tailed) dari parameter tinggi tanaman jagung sebesar 0,163>0,05 maka H0 diterima dan Ha ditolak. Dengan demikian dapat disimpulkan bahwa tidak ada perbedaan yang nyata (signifikan) antara agroforestri penanaman lorong (alley cropping) dan tumpang sari. Nilai Sig. (2tailed) jumlah daun tanaman jagung sebesar $0,000<0,05$ maka H0 ditolak dan Ha diterima. Dengan demikian dapat 
disimpulkan bahwa terdapat perbedaan yang nyata (signifikan) antara jumlah daun tanaman jagung pada sistem agroforestri penanaman lorong (alley cropping) dan tumpang sari. Nilai Sig. (2-tailed) diameter batang tanaman jagung sebesar $0,000<$ 0,05 maka H0 ditolak dan Ha diterima. Dengan demikian dapat disimpulkan bahwa ada perbedaan yang nyata (signifikan) antara diameter batang tanaman jagung pada sistem agroforestri penanaman lorong (alley cropping) dan tumpang sari. Jika nilai probabilitas signifikansi $<0,05$ maka ini berarti suatu variabel independen merupakan penjelas yang signifikan terhadap variabel dependennya (Desiskawati, 2015). Alley cropping mampu memperbaiki sifat fisik dan kimia tanah, aktifitas biologi tanah serta dapat meningkatkan dan mempertahankan produksi tanaman pangan (Haerani, 2017).

\section{SIMPULAN}

Rata-rata tertinggi tinggi tanaman, jumlah daun, dan diameter batang jagung terdapat pada sistem agorforestri penanaman lorong (alley cropping) yaitu $1,03 \mathrm{~m}, 7,31$, dan $1,59 \mathrm{~cm}$. Tidak terdapat perbedaan yang signifikan antara tinggi tanaman jagung pada sistem agroforestri penanaman lorong (alley cropping) dan tumpang sari. Terdapat perbedaan yang signifikan antara jumlah daun dan diameter batang tanaman jagung pada sistem agroforestri penanaman lorong (alley cropping) dan tumpang sari.

\section{DAFTAR PUSTAKA}

Departemen Kehutanan Direktorat Jenderal Rehabilitasi Lahan dan Perhutanan Sosial Balai Pengelolaan Daerah Aliran Sungai Unda Anyar, (2003). Rancangan Model Pengelolaan Mikro Daerah Aliran Sungai Tukad Sumaga. Denpasar.

Desiskawati Y. (2015). Pengaruh kinerja keuangan berdasarkan islamicity performance index terhadap pengungkapan Islamic social reporting: Studi kasus pada perbankan syariah di Indonesia. Journal, Universitas Islam Negeri Maulana Malik Ibrahim. Malang.

Haerani, N. (2017). Alley Cropping Meningkatkan Resiliensi Produksi Pertanian Pada Lahan Kering. Journal, Universitas Al Asyariah Mandar.Sulawesi Barat.

Hairiah K., \& Rahayu, S. (2007). Pengukuran 'Karbon Tersimpan' di Berbagai Macam Penggunaan Lahan. Bogor. World Agroforestry CentreICRAF, SEA Regional Office, University of Brawijaya, Unibraw, Indonesia.

Indriyanto. (2005). Ekologi Hutan. Bumi Aksara. Bandar Lampung.

Mokoginta, M. M. (2016). Pengelolaan Agroforestry. Budi Utama. Kotamobagu

Rahayu, S., Widodo, R. H., van Noordwijk, M., Suryadi, I., \& Verbist, B. 2009. Monitoring Air di Daerah Aliran Sungai. World Agroforestry Centre - 
I WAYAN GEDE WIRYANATA et al. Perbedaan Tinggi, Jumlah Daun, dan Diameter...

Southeast Asia Regional Office. Bogor.

Sarwono, J., \& Herlina, B. (2012). Statistik Terapan Aplikasi Untuk Riset Skripsi, Tesis dan Disertasi Menggunakan SPSS, AMOS dan Excel. Jakarta.

Triwanto, J. (2019). Agroforestry. Universitas Muhammadiyah Malang. Malang.

Wang, L., Tang L., Wang, X., \& Chen, F. (2010). Effect of alley crop planting on soil and nutrient losses in the citrus orchards of the Three Georges Region. Soil \& Tillage Research 110 (2010): 243-250. Elsevier. 